\title{
Knowledge and practice regarding menstrual hygiene among adolescent girls of rural field practice area of RIMS, Raipur (C. G.), India
}

\author{
Neerja Agarwal ${ }^{1}$, Nutan Soni ${ }^{1 *}$, S. P. Singh ${ }^{2}$, G. P. Soni ${ }^{3}$
}

\author{
${ }^{1}$ Department of Obstetrics and Gynecology, RIMS, Raipur, Chhattisgarh, India \\ ${ }^{2}$ Department of Community Medicine, RIMS, Raipur, Chhattisgarh, India \\ ${ }^{3}$ Department of Community Medicine, Govt. Medical College, Rajnandgaon, Chhattisgarh, India
}

Received: 26 March 2018

Accepted: 01 May 2018

*Correspondence:

Dr. Nutan Soni,

E-mail: dhiraj.bhawnani@gmail.com

Copyright: () the author(s), publisher and licensee Medip Academy. This is an open-access article distributed under the terms of the Creative Commons Attribution Non-Commercial License, which permits unrestricted non-commercial use, distribution, and reproduction in any medium, provided the original work is properly cited.

\section{ABSTRACT}

Background: Adolescent age group among girls have been recognized as a special period which signifies the transition from girlhood to womanhood. Menstruation is generally considered as unclean in the Indian society. Most of the adolescent girls had incomplete and inaccurate information about the menstrual physiology and hygiene as reported by many Indian studies. Very few authors have included the detailed aspects of the menstrual practices among adolescent girls.

Methods: The current Community based cross sectional study was conducted by department of obstetrics and Gynaecology in connection with department of community medicine, Raipur Institute of Medical Science, Raipur (C.G), India. Among the adolescent school going girls in the field practice area of the Rural Health Unit and Training Centre during study period of 6 months from July 2017 to December 2017. 263 girls from the above mentioned schools, of the 8th and 9th standards, were selected for the study.

Results: Majority of the school going adolescent girls belong to 13 and 14 years of age. 50.95\%, 21.67\% and $12.93 \%$ girls reported that they had their menarche at the age of 13 year, 12 year and 14 year respectively. Majority of the girls were using cloth $(49.81 \%)$ and only $17.87 \%$ were using sanitary napkins. Cleaning of external genitalia was not satisfactory in $32.70 \%$ of the girls. Only $58.17 \%$ girls used both soap and water for cleaning the genitalia. Pain in abdomen $(59.70 \%$ ) was found to be the most frequent complaint during menstruation.

Conclusions: Knowledge on menstruation is sub-optimal and the practices are unacceptable for proper hygiene among study subjects. Menstrual hygiene is an important issue needs to be ensured.

Keywords: Adolescent girls, Menstrual hygiene, Knowledge, Practices

\section{INTRODUCTION}

Adolescent age group among girls have been recognized as a special period which signifies the transition from girlhood to womanhood. Menstruation is generally considered as unclean in the Indian society.

Prevalent taboos like isolation of the menstruating girls and restrictions being imposed on them have negative impact over adolescent regarding menstruation and menstrual hygiene can result in preventable reproductive tract infection and infertility. ${ }^{1}$ Several studies have reported restrictions during the daily activities. Apart from these, they believe in specified taboos at menarche and menstruation. ${ }^{2}$

There is a gap in the knowledge about menstruation among adolescent girls. Many studies have reported this gap and they showed that there was a low level of awareness about menstruation among the girls when they first experienced it. $^{3-5}$ Social prohibitions and the negative attitude of parents in discussing the related 
issues openly, have blocked the access of adolescent girls to the appropriate information. ${ }^{6}$ Many studies conducted in India showed significant association between infection and menstrual hygiene status. ${ }^{6-9}$

Most of the adolescent girls had incomplete and inaccurate information about the menstrual physiology and hygiene as reported by many Indian studies. It also revealed that mothers, television, friends, teachers and relatives were the main sources which provided information on menstruation to the adolescent girls. ${ }^{6,10,11}$ Good hygienic practices such as the use of sanitary pads and adequate washing of the genital area are essential during menstruation.

Women and girls of the reproductive age need access to clean and soft, absorbent sanitary products which can in the long run, protect their health.,12 However, the attention on this issue is insufficient. ${ }^{13}$ A key priority for women and girls is to have the appropriate knowledge, facilities and the environment to manage menstruation hygienically and with dignity.

Very few authors have included the detailed aspects of the menstrual practices among adolescent girls. It was therefore considered as relevant to investigate the menstruation related knowledge and practices among the school going adolescent girls.

\section{Objectives}

Objectives of present study were to assess the knowledge and the practices of menstrual hygiene among school going adolescent girls and to assess the restrictions which were practised by adolescent school girls during menstruation.

\section{METHODS}

The current community based cross sectional study was conducted by department of obstetrics and Gynaecology in connection with department of community medicine, Raipur Institute of Medical Science, Raipur (C.G), India. Among the adolescent school going girls in the field practice area of the Rural Health Unit and Training Centre during study period of 6 month from July 2017 to December 2017.

However, the students from rural areas also attended the schools which were included in this study setting. In this study area, there was only a single government school. Hence, this School was purposively selected for the study.

\section{Study population}

263 girls from the above mentioned schools, of the 8th and 9th standards, were selected for the study. Predesigned, pretested and structured questionnaire was used in the study. The data collection technique was a personal interview of the study subjects.

\section{Methodology}

After taking permission from the school authorities, the class teachers of the 8th and 9th standards were explained the purpose of the study and verbal consents of girl students were obtained.

The purpose of the study and the nature of the information which had to be furnished by the study subjects were explained to them. The research protocol was approved by the Institutional Ethics Committee.

Data was recorded in MS Excel and checked for its completeness and correctness then it was analysed by suitable statistical software and $\mathrm{P}$ value $<0.05$ was considered as a statistically significant.

\section{RESULTS}

Table 1: Demographic characteristics of the study subjects.

\begin{tabular}{|lll|}
\hline Characteristics & No. & $\%$ \\
\hline Age in years & & \\
\hline 12 & 13 & 4.94 \\
\hline 13 & 87 & 33.08 \\
\hline 14 & 119 & 45.25 \\
\hline 15 & 33 & 12.55 \\
\hline$\geq 16$ & 11 & 4.18 \\
\hline Education status of mother & & \\
\hline Literate & 247 & 93.92 \\
\hline Illiterate & 16 & 6.08 \\
\hline
\end{tabular}

Majority of the school going adolescent girls belongs to 13 and 14 year of age. A majority of the mothers of the study girls were educated and $6.08 \%$ of the mothers were illiterate (Table 1).

Majority girls had menarche at age of 13 year.

It was evident that only $137(52.09 \%)$ of the girls were aware about menstruation before menarche and the most important sources of the information were mothers $(41.61 \%)$, sisters $(12.41 \%)$ and friend $(13.87 \%)$.

While the other sources of information were Teachers, Relatives, TV, Movie, Magazines and others. $42.59 \%$ of girls were scared at the time of their first menstrual cycle.

Another $19.77 \%, 16.35 \%$ and $14.07 \%$ of girls felt usual, irritation/disgusted and discomfort respectively. Regarding restrictions $57.79 \%$ of the girls responded that they do not attend Religious occasion during menstruation. $51.33 \%$ of the girls did not visit/attend others home, family functions and any type of Physical 
activity. Surprisingly $16.35 \%$ of girls reported that they do not have any restrictions (Table 2).

Majority of the girls were using cloth $(49.81 \%)$ and only $17.87 \%$ were using sanitary napkins. Cleaning of external genitalia was not satisfactory (frequency of cleaning of external genitalia is nil or $<2$ times/day) in $32.70 \%$ of the girls.

Only $58.17 \%$ girls used both soap and water for cleaning the genitalia. Only $48.29 \%$ girls satisfactory disposed the used cloth pieces or sanitary napkins (Table 3 ).

Table 2: Information about menarche and perception about menstruation $(n=263)$.

\begin{tabular}{|c|c|c|}
\hline Variable & No. & $\%$ \\
\hline \multicolumn{3}{|l|}{ Age of menarche (years) } \\
\hline$\leq 11$ & 21 & 7.98 \\
\hline 12 & 57 & 21.67 \\
\hline 13 & 134 & 50.95 \\
\hline 14 & 34 & 12.93 \\
\hline$\geq 15$ & 17 & 6.46 \\
\hline $\begin{array}{l}\text { Awareness about menstruation } \\
\text { before menarche }\end{array}$ & 137 & 52.09 \\
\hline \multicolumn{3}{|c|}{ Source of information before menarche* $(n=137)$} \\
\hline Mother & 57 & 41.61 \\
\hline Sister & 17 & 12.41 \\
\hline Friends & 19 & 13.87 \\
\hline Teachers & 9 & 6.57 \\
\hline Relatives & 4 & 2.92 \\
\hline TV & 7 & 5.11 \\
\hline Movie & 3 & 2.19 \\
\hline Magazines and others & 21 & 15.33 \\
\hline \multicolumn{3}{|l|}{ Reaction to 1st menstruation } \\
\hline Scared & 112 & 42.59 \\
\hline Usual & 52 & 19.77 \\
\hline Discomfort & 37 & 14.07 \\
\hline Irritation/disgusted & 43 & 16.35 \\
\hline Other than above & 19 & 7.22 \\
\hline \multicolumn{3}{|c|}{$\begin{array}{l}\text { Restrictions and taboos (avoided activities) during } \\
\text { menstruation }\end{array}$} \\
\hline Religious occasion & 152 & 57.79 \\
\hline Physical activity/playing & 33 & 12.55 \\
\hline Schooling & 19 & 7.22 \\
\hline Attending family functions & 39 & 14.83 \\
\hline No restrictions at all & 43 & 16.35 \\
\hline Household work & 11 & 4.18 \\
\hline Keeping fast & 7 & 2.66 \\
\hline Avoiding visit to others home & 63 & 23.95 \\
\hline Avoiding regular bath & 17 & 6.46 \\
\hline
\end{tabular}

Pain in abdomen $(59.70 \%)$ was found to be the most frequent complaint during menstruation followed by headache / irritation (23.57\%), loss of appetite (11.79\%) and leg cramps $(11.03 \%)$ etc (Table 4$)$.
Table 3: Menstrual hygiene and practices during menstruation.

\begin{tabular}{|lll|}
\hline \multicolumn{2}{|l|}{ Practice of menstrual hygiene } & No. \\
\hline Use of material during menstruation & \\
\hline Sanitary napkins & 47 & 17.87 \\
\hline New cloths & 28 & 10.65 \\
\hline Reuse old cloth & 103 & 39.16 \\
\hline Alternate use of above all & 85 & 32.32 \\
\hline Cleaning of external genitals & & \\
\hline Not at all & 18 & 6.84 \\
\hline$<2$ times & 68 & 25.86 \\
\hline$>2$ times & 94 & 35.74 \\
\hline As per convenience and privacy & 83 & 31.56 \\
\hline Cleaning with & & \\
\hline Soap and water & 153 & 58.17 \\
\hline Only water & 84 & 31.94 \\
\hline Piece of paper & 7 & 2.66 \\
\hline Piece of cloth & 19 & 7.22 \\
\hline Disposal of menstrual material used & \\
\hline Throwing in dustbin & 124 \\
\hline Flushing in toilets & 31 & 47.15 \\
\hline Washing and reusing & 82 \\
\hline Don't want to tell & 23 & 31.79 \\
\hline Dumping/burning & 3 & 8.75 \\
\hline
\end{tabular}

Table 4: Health problems during menstruation.

\begin{tabular}{|lll|}
\hline Complications & No. & $\%$ \\
\hline Pain in abdomen & 157 & 59.70 \\
\hline Nausea /vomiting & 15 & 5.70 \\
\hline Headache/irritation & 62 & 23.57 \\
\hline Palpitaion/giddiness & 13 & 4.94 \\
\hline Leg cramps & 29 & 11.03 \\
\hline Loss of appetite & 31 & 11.79 \\
\hline
\end{tabular}

\section{DISCUSSION}

The current study reveals that the age of menstruating girls ranged from 12 to 16 and 17 years. A similar study reported that the age of the menstruating girls ranged from 12 to 17 years with the majority of the girls being between 13 to 15 years of age.

Nearly similar finding were also reported by Ghattargi et al. The present study observed that the age of menarche ranged from 11 to 15 years while Ghattargi et al observed that the age of menarche in their study ranged from 12 to 17 years with the maximum number of girls between 13 to 15 year of age which is nearly similar to the finding of the current study. ${ }^{10}$

Age of menarche of the participants ranged between 11 to 15 year $(88.5 \%)$ according to study by Ramachandra et al. A similar comparable study was also conducted in Rajesthan by Khanna et al (mean age at menarche to be 13.2 yeaar). 5,12 
A study by Ramachandra et al showed that only $33.27 \%$ the urban had awareness about menstruation prior to menarche while in current study, the awareness among girls regarding menstruating menarche was $52.09 \% .^{12}$

Interestingly a study conducted by Adirija et al, reported that $72.01 \%$ of the urban participants and only $39.01 \%$ rural participants had knowledge prior to menstruation. ${ }^{13}$

Mothers followed by friends, Magazines and sisters were the more sources of information in our study. Similar findings were observed by other authors where mother was the first informant.

Different reactions to menarche may depend on the extent to which the adolescent girls have been prepared for the same. In the present study, majority of the girls were scared during their first menstruation while fear and panic was the reaction observed in the study conducted by Dube et al and Ghattargi et al. Majority of the participants expressed negative reaction to menstruation. It showed the fact that girls with no previous awareness about menstruation felt more negative reactions. ${ }^{14,10}$

In this study, majority of the girls $57.79 \%$ did not attend religious functions during their cycle. $23.95 \%, 14.83 \%$ and $12.55 \%$ girls were not attending others home, family functions and physical activity respectively. Surprisingly, $16.35 \%$ girls do not have any kind of restrictions during their menstruation. Ghattargi et al found that $21.06 \%$ rural girls were not practising taboos which was slightly higher than the current study. ${ }^{10}$

Less than $20 \%$ girls use sanitary napkins available in the market. Khanna et al and Quazi et al in their current study found that more than three fourth of girls use cotton cloth and reuse them after washing. ${ }^{5,15} 32.7 \%$ of the girls were not following satisfactory cleanliness of external genitalia (frequency of cleaning is nil or $<2$ times a day). Soap and water was used for cleaning by $58.17 \%$ of girls. $48.29 \%$ girls properly disposed the cloth pieces or sanitary pads used. Nearly similar findings were observed in the study of Dasgupta et al. ${ }^{11}$

Pain in abdomen $(59.70 \%)$ was found to be the most frequent complaint during menstruation followed by headache/irritation $(23.57 \%)$, loss of appetite $(11.79 \%) \&$ leg cramps $(11.03 \%)$ etc. Majority of the girls reported experiencing stomach ache $(63.5 \%)$ followed by nausea (41.5\%), pain in leg (12.0\%), loss of appetite $(24.0 \%)$ and very few stated having headache as reported by Rajni Dhingra and et al (2009). ${ }^{1}$

\section{CONCLUSION}

It can be concluded that among the adolescent girls, the knowledge on menstruation is sub-optimal and the practices are unacceptable for proper hygiene. Menstrual hygiene is an important issue needs to be ensured. A variety of factors are known to affect menstrual behaviours. Awareness regarding the need for information on healthy menstrual practices is very important. It is essential to design a mechanism to address and for the access of healthy menstrual practices. Periodic gynaecology check-up should be recommended to all school going girls. It should be followed by appropriate remedial measures.

\section{ACKNOWLEDGMENTS}

The authors would like to thank all the faculty and technical staff members of the Department of Obstetric and Gynaecology and Department of community medicine, RIMS, Raipur (C.G.) India, for their immense cooperation and support during the entire study.

Funding: No funding sources

Conflict of interest: None declared

Ethical approval: The study was approved by the Institutional Ethics Committee

\section{REFERENCES}

1. Dhingra R, Kumar A. Knowledge and practices related to menstruation among tribal (Gujjar) adolescent girls. Etho-Med. 2009;3(1):43-8.

2. Singh AJ. The place of menstruation in the reproductive lives of women of rural north India. Indian J Community Med. 2006;31(1):10-4.

3. Ahuja A, Tiwari S. Awareness about pubertal changes among adolescent girls. J Family Welfare. 1995;41(1):46-50.

4. Chaudhari RH. Socio-economic demographic and reproductive health profile of adolescents in the SAARC countries. Paper presented in south Asia Conference on Adolescents, 21-23 July 1998; New Delhi, India, 1998.

5. Khanna A, Goyal RS, Bhawsar R. Menstrual practices and reproductive problems: A study of adolescent girls in Rajasthan. J Health Management. 2005;7(1):91-7.

6. Mudey AB, Keshwani N, Mudey GA, Goyal RC. A cross-sectional study on the awareness regarding safe and hygienic practices amongst school going adolescent girls in the rural areas of Wardha district. Global J Health Sci. 2010;2(2):225-31.

7. Bhatia JC, Cleland J. Self reported symptoms of gynecological morbidity and their treatment in south India. Studies Family Planning 1995;26(4):491-5.

8. Mehara S. Adolescent Girl: An Indian perspective. MAMTA Health Institute for Mother and Child, Saket, New Delhi. 1995: 75-78.

9. Green EM. Watering the neighbor's garden, New Delhi, 1997; Population Council (Working paper No.7); 1997.

10. Ghattargi $\mathrm{CH}$, Deo DS. Preparation and Practices regarding Menstruation: A comparative study in Rural and Urban Adolescent Girls. Indian J Community Med. 2005;30(1):10-4. 
11. Dasgupta A, Sarkar M. Menstrual Hygiene: How Hygienic is the Adolescent Girl? Indian J Community Med. 2008;33(2):77-80.

12. Ramachandra K, Gilyaru S, Eregowda A, Yathiraja S. A study on knowledge and practices regarding menstrual hygiene among urban adolescent girls. Int J Contemp Pediatr. 2016;3:142-5.

13. Datta A, Manna N. Menstruation and menstrual hygiene among adolescent girls of West Bengal, India: A school based comparative study. GJMEDPH. 2012;1(5):50-7.

14. Dube S, Sharma K. Knowledge, attitude and practice regarding reproductive health among Urban and rural girls: a comparative study. Ethno Med. 2012;6(2):8594.

15. Quazi SZ, Gaidhane A, Singh D. Believes and Practices regarding menstruation among adolescent girls of high school and Junior college of rural areas of Thane district. J DMIMSU. 2006;2:67-71

Cite this article as: Agarwal N, Soni N, Singh SP, Soni GP. Knowledge and practice regarding menstrual hygiene among adolescent girls of rural field practice area of RIMS, Raipur (C. G.), India. Int J Reprod Contracept Obstet Gynecol 2018;7:231721. 